\title{
SIMILARITIES IN FORM SYMBOLISM AMONG VARIOUS LANGUAGES AND GEOGRAPHICAL REGIONS
}

\author{
Tadasu OYAMA ${ }^{1)}$, Tiziano AGOSTINI ${ }^{2)}$, Akiko KAMADA ${ }^{3)}$, Slobodan MARKOVIĆ(4), \\ Eiko OSAKA ${ }^{\text {(), }}$, Shojiro SAKURAI'), Ivan SARMÁNY-SCHULLER ${ }^{\text {) }}$, and Viktor SARRIS ${ }^{8)}$ \\ ${ }^{1)}$ Nihon University, Japan, ${ }^{2)}$ University of Trieste, Italy, ${ }^{3)}$ Bunkyo University, Japan, \\ 4) University of Belgrade, Serbia, ${ }^{5}$ Surugadai University, Japan, ${ }^{6}$ Kaohsiung Medical University, Taiwan, \\ ${ }^{7)}$ Slovak Academy of Science, Slovakia, ${ }^{8} \mathrm{~J}$. W. Goethe University, Germany
}

\begin{abstract}
Similarities of language-independent form symbolism were tested across different geographical regions. In Experiment 1, word-form matching between 10 abstract words and 16 computer-generated nonsense forms was performed by between 61 and 107 undergraduate or volunteer participants in nine geographic regions of the world. Participants were native speakers of one of eight different languages: Japanese, Chinese, Korean, English, Italian, German, Serbian and Slovakian. The results demonstrated similar trends across languages and geographic regions. The small but significant differences between Eastern and Western groups found in Experiment 1 could be attributed to differences between them in the affective meanings of words rather than forms, as suggested by the results of Experiment 2. Experiment 2 involved participants (49 to 116 undergraduates from Japan, Taiwan, the US and Serbia) performing the 11-scale Semantic Differential technique on 10 words and eight of the 16 forms used in Experiment 1. It was concluded that the cross-regional similarity of form symbolism is based on the similarity of affective meanings of forms across different regions and languages.
\end{abstract}

Key words: form, shape, symbolism, affective meaning

Sensory stimuli give people certain feelings in addition to their specific sensory experiences. For example, the color red induces warm, energetic, and exciting feelings, while the color blue gives cool, quiet, and peaceful feelings in people of many geographical regions (Collier, 1996; Lai, 2003; Kwon \& Park, 2005; Oyama, 2003; Schale, 1961; Zwimpfer, 1985). Red frequently is used to symbolize passion, anger and danger, while blue is used to symbolize calmness, sadness and safety. Forms (i.e. shapes) also give people various impressions and have various symbolic meanings. Köhler (1929), Fox (1935) and Oyama \& Haga (1963), among many other investigators, found strong consistent associations between angular forms and sharp nonsense sounds like

We are most grateful to Saburo Iwawaki, Showa Women's University, Japan, Yu Kang-Min, Yonsei University, and Yoko Okuyama, Dongduk Women's University, South Korea, Sarah Trenholm, Ithaca College, US, Hiroshi Hasegawa, Curtin University of Technology, and Romit Dasgupta, University of Western Australia, Australia, and the late Franco Purghé, University of Torino, Italy, for their assistance in data collection, as well as in the translation of questionnaires. Thanks also to Hisao Miyano, National Center for University Entrance Examinations, Japan for his kind advices on the statistical analysis of the data, to C. H. Liu, University of Hull, UK, for his helpful comments on an earlier version of the manuscript, and to Cha Jeong Min for her useful information on the Korean literature of color studies.

Correspondence concerning this article should be addressed to Tadasu Oyama, 16-18 Oyamacho, Shibuyaku, Tokyo 151-0065, Japan (e-mail: oyama@gssc.nihon-university.ac.jp). 
takete, and between round forms and soft nonsense sounds like maluma. These results suggested that common synesthetic and symbolic processes intervene between form perception and phonetic perception. Oyama \& Haga (1963) also studied the affective meanings of 14 line-drawings using the Semantic Differential technique with Japanese students. They found that symmetrical regular forms were evaluated more positively but felt as less active than asymmetrical irregular forms, and that straight-line forms were rated as harder and sharper than round forms. More recently Lindauer (1990) also conducted a similar experiment and demonstrated the same differences between the straight and rounded forms.

Consistent relationships have been found between the meanings of English or German words and the geometrical features of line drawings that were matched to them by American and German students. These findings have been explained from the perspective of physiognomic perception (Scheerer \& Lyons, 1957; Werner \& Kaplin, 1963). Physiognomic perception of forms has also been discussed in relation to metaphors and symbolic activity (Marks, 1996; Seitz, 1998). Liu and Kennedy (1993, 1997) compared the goodness-of-fit of a circle and a square as symbols for 40 words in English-speaking Canadian students. They found the circle to be a good symbol for softness, happiness, love, etc, while the square was found to be a good symbol for hardness, sadness, hate, etc. Kennedy, Liu, Challis, and Kennedy (2002) applied the same technique to three different language groups (Danish-, Slovene-, and Japanese-speaking students in Denmark, Slovenia and Japan) and found results very similar to those of the English-speaking students and to one another group. Correlations between the ratings of goodness-of-fit for each group for the same forms ranged from .77 to .90 . This remarkable consistency across different languages and different regional groups suggest cross-language and crossregional similarity of form symbolism.

The present study was conducted to test the similarity of form symbolisms using various forms in a larger number of language groups in different geographical regions of the world, using the Word-Form Matching method (Experiment 1) and the Semantic Differential technique (Experiment 2), both of which have been shown by Oyama, Yamada, and Iwasawa (1998a) to be useful for the investigation of form symbolism in Japanese participants.

This study was not designed for the explicit purpose of comparing Asian and European cultures. The nine geographical regions in the study were selected for the highest level of support and interest in this study shown by collaborating researchers and participants.

\section{EXPERIMENT 1: WORD-FORM MATCHING}

Nine participant groups comprised of individuals from nine geographic regions of the world matched 16 forms to 10 words. The participants spoke one of eight different languages (Japanese, Chinese, Korean, English, Italian, German, Serbian and Slovakian). 


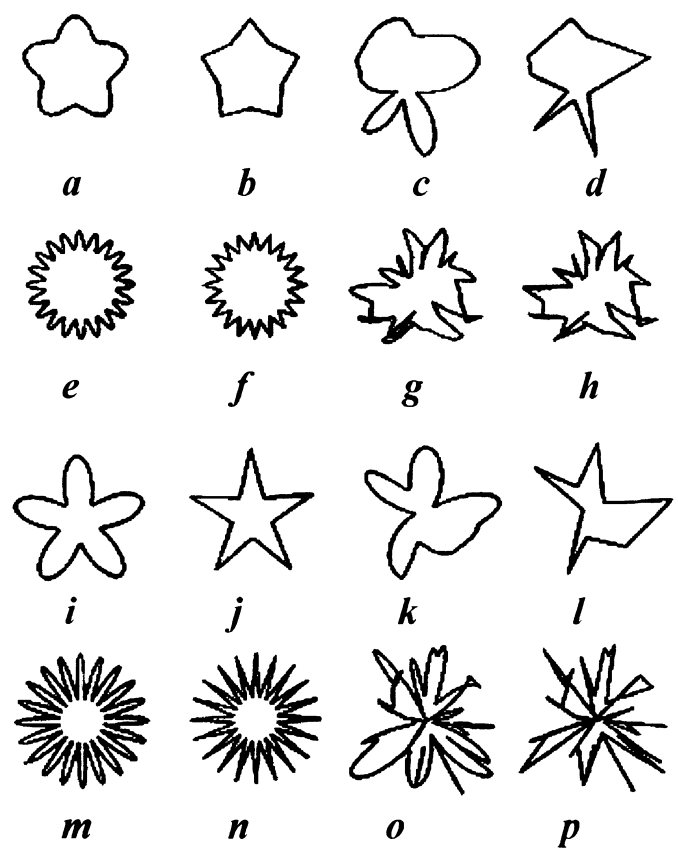

Fig. 1. Computer-generated stimulus forms used in the word-form matching (Oyama, Yamada, \& Iwasawa, 1998a).

\section{Method}

Participants. Participants were mostly undergraduate students from nine different regions of the world. Their ages were mainly 17 to 25 years although some older persons (late twenties to fifties) also participated. Participants were 107 in Japan, 94 in Taiwan, 90 in South Korea, 79 in USA, 61 in Australia, 90 in Italy, 75 in Germany, 100 in Serbia, and 61 in Slovakia (males consisted between 21\%-50\% of each group). All participants were native speakers of the primary language of each region. The data of participants who provided ambiguous answers, or who was not a native speaker of the language in question, were excluded from the analyses and are not included in the above counts.

Stimulus materials. Six of the 10 stimulus words selected for this study were chosen from among words used in previous color-symbolism studies (Tanaka, Oyama, \& Osgood,1963; Oyama, Tanaka, \& Haga, 1963 ) and four were newly added. They were 1) Happiness, 2) Anxiety, 3) Eternity, 4) Anger, 5) Creation, 6) Loneliness, 7) Surprise, 8) Destruction, 9) Fear, and 10) Time. Their translations into the other seven languages are shown in Table 1. The stimulus words and task instructions initially were translated from Japanese into English by the first author and edited using native English speakers. They were then translated from English into the Western languages by native speakers of respective languages, while the Chinese and Korean words were translated by native speakers of these languages directly from Japanese.

The 16 computer-generated stimulus forms are the same as those in Oyama et al. (1998a), and are shown in Fig. 1. The original stimulus form (Form $a$ shown in Fig. 1) consisted of five cycles of a sinusoidal wave superimposed on a circle. Fifteen variations were produced from this original form, with the frequency and amplitude of the waveform varied. In addition, in eight of the forms (the third and fourth columns of Fig. 1), random modulations were introduced to the local frequency and amplitude of the waveform. Curved lines were also changed into straight lines in four regular and four irregular forms (the second and fourth columns, respectively, of Fig. 1), keeping feature points at constant positions as shown by Oyama, Miyano, \& Yamada (2003). Oyama et al. (2003) applied the multi-dimensional scaling technique to analyze similarity data among the 16 computer-generated abstract forms shown in Fig. 1. A three-dimensional solution was 
Table 1. Stimulus Words in Eight Languages of Nine Geographical Regions used in the Word-Form Matching Experiment

\begin{tabular}{|c|c|c|c|c|c|c|c|}
\hline Japan & Taiwan & South Korea & US/Australia & Italy & Germany & Serbia & Slovakia \\
\hline Japanese & Chinese & Korean & English & Italian & German & Serbian & Slovakian \\
\hline 幸福 & 幸福 & 행복 & Happiness & FELICITA' & Glückseligkeit & SREĆA & Št'astie \\
\hline 不安 & 焦慮 & 불안 & Anxiety & ANSIA & Ängstlichkeit & STREPNJA & Úzkost ${ }^{\star}$ \\
\hline 永遠 & 永恆 & 영 원 & Eternity & ETERNITA' & Ewigkeit & VEČNOST & Večnost" \\
\hline 怒り & 憤怒 & 분노 & Anger & RABBIA & Ärger/Wut & BES & Hnev \\
\hline 創作 & 創造 & 창작 & Creation & CREATIVITA' & Schöpfung & STVARALAŠTVO & Stvorenie \\
\hline 孤独 & 孤獨 & 고독 & Loneliness & SOLITUDINE & Einsamkeit & USAMLJENOST & Samota \\
\hline 驚き & 驚訝 & 놀람 & Surprise & SORPRESA & Überraschung & IZNENAĐENJE & Prekvapenie \\
\hline 破壊 & 破壞 & 파괴 & Destruction & DISTRUZIONE & Zerstörung & RAZARANJE & Zničenie \\
\hline 恐れ & 恐懼 & 두려움 & Fear & PAURA & Furcht/Besorgnis & STRAH & Strach \\
\hline 時間 & 時間 & 시간 & Time & TEMPO & Zeitdauer & VREME & Čas \\
\hline
\end{tabular}

obtained. These three dimensions were named "Complexity", "Regularity" and "Curvedness", which are variables that have frequently been indicated as important in form perception (Zusne, 1970). These perceptual dimensions corresponded to four physical parameters: "Complexity" corresponded primarily to the frequency of the wave and to a lesser extent its amplitude, "Curvedness" corresponded to the stimulus curvature, and "Regularity" corresponded to the absence of random modulations in the form (Oyama, et al., 2003).

Procedure. Participants in each geographic region were tested in groups in classrooms. They were given a questionnaire that contained blanks for the participant's name, gender, age, and native language on the top portion, followed by the following instructions printed in each language:

"You will find 16 figures lettered $a$ to $p$ on the next sheet. We are interested in seeing how you assign figures to the words listed below. Please select the figure that seems to best fit each word and write the letter of the selected figure in the blank beside the corresponding word. You may choose the same figure for different words. Please complete every item".

The 10 words shown in Table 1 were presented in each language below the instructions, printed in the same letter style and order as in the table. The 16 stimulus forms were printed on the following page as in Fig. 1.

\section{RESULTS}

The results showed similar trends across the different geographic regions and different languages. Tables 2 and 3 show the most frequently matched three forms for each of the 10 words in the Eastern and Western geographical regions, respectively. Many participants in each region matched regular forms like $a, i, j, m$, and $n$ to the words "Happiness" and "Eternity", complex regular straight-line forms like $f$ and $n$ to the word "Surprise", simple irregular forms like $c, k$, and $l$, to the words "Creation" and "Loneliness", and complex irregular (largely straight-line) forms like $h, o$ and $p$ to the words "Anger" and "Destruction". Moderately complex regular forms like $e$ and $f$ were 
Table 2. The Most Frequent Three Forms Matched to the 10 Stimulus Words in the Three Eastern Regions

\begin{tabular}{|c|c|c|c|c|c|c|c|c|c|}
\hline \multirow{2}{*}{$\begin{array}{c}\text { East } \\
\text { Happiness }\end{array}$} & \multicolumn{3}{|c|}{ Japan $(\mathrm{n}=107)$} & \multicolumn{3}{|c|}{ Taiwan $(n=94)$} & \multicolumn{3}{|c|}{ South Korea $(\mathrm{n}=90)$} \\
\hline & $\mathrm{a}(51)$ & $\mathrm{m}(11)$ & $\mathrm{n}(10)$ & $\mathrm{a}(62)$ & $\mathrm{b}(10)$ & $\mathrm{m}(9)$ & $\mathrm{a}(74)$ & $\mathrm{i}(10)$ & $\mathrm{b}, \mathrm{e}(5)$ \\
\hline Anxiety & $\mathrm{g}(51)$ & o (8) & $\mathrm{h}, \mathrm{k}(7)$ & h (26) & $\mathrm{g}, \mathrm{p}(22)$ & & $\mathrm{g}(34)$ & $\mathrm{p}(19)$ & h,o (16) \\
\hline Eternity & $\mathrm{m}(20)$ & $\mathrm{j}(14)$ & $\mathrm{n}(12)$ & $\mathrm{j}(23)$ & n (19) & $\mathrm{a}(13)$ & e (20) & $\mathrm{m}(18)$ & $\mathrm{n}(14)$ \\
\hline Anger & $\mathrm{p}(55)$ & $\mathrm{n}(20)$ & $\mathrm{h}(11)$ & $\mathrm{p}(51)$ & o (21) & h, n (11) & $\mathrm{p}(40)$ & o (22) & $\mathrm{n}(16)$ \\
\hline Creation & $\mathrm{k}(16)$ & $\mathrm{c}, \mathrm{o}(11)$ & & $1(19)$ & $\mathrm{n}(12)$ & $\mathrm{f}, \mathrm{k}(10)$ & $\mathrm{k}(24)$ & $\mathrm{c}(10)$ & $\mathrm{i}, \mathrm{j}, 0(8)$ \\
\hline Loneliness & $1(24)$ & $\mathrm{d}(13)$ & c (10) & $1(28)$ & $\mathrm{c}, \mathrm{d}(12)$ & & $1(22)$ & $\mathrm{d}(13)$ & $\mathrm{b}(11)$ \\
\hline Surprise & n (33) & $\mathrm{f}(29)$ & $\mathrm{p}(9)$ & $\mathrm{n}(28)$ & $\mathrm{f}(17)$ & $1, \mathrm{~m}(9)$ & $\mathrm{n}(42)$ & $\mathrm{f}(11)$ & o (10) \\
\hline Destruction & $\mathrm{p}(71)$ & $\mathrm{h}, \mathrm{o}(8)$ & & $\mathrm{p}(39)$ & o (18) & $\mathrm{h}(15)$ & $\mathrm{p}(18)$ & o (13) & $\mathrm{h}(11)$ \\
\hline Fear & $\mathrm{g}(30)$ & $\mathrm{h}(25)$ & o (13) & $\mathrm{g}(23)$ & o (19) & $\mathrm{h}(18)$ & $\mathrm{h}(28)$ & $\mathrm{g}(23)$ & $1, \mathrm{n}, \mathrm{o}(9)$ \\
\hline Time & $\mathrm{e}, \mathrm{f}(14)$ & $\mathrm{m}(13)$ & & e (24) & $\mathrm{f}(22)$ & n (17) & e (28) & $f(16)$ & $\mathrm{j}, \mathrm{n}(9)$ \\
\hline
\end{tabular}

Note. The numbers in parentheses indicate the percentages of matches to the specified forms.

Table 3. The Most Frequent Three Forms Matched to the 10 Stimulus Words in the Six Western Regions

\begin{tabular}{|c|c|c|c|c|c|c|c|c|c|}
\hline \multirow{2}{*}{$\begin{array}{c}\text { West } \\
\text { Happiness }\end{array}$} & \multicolumn{3}{|c|}{ US $(n=79)$} & \multicolumn{3}{|c|}{ Australia $(n=61)$} & \multicolumn{3}{|c|}{ Italy $(\mathrm{n}=90)$} \\
\hline & m (39) & n (18) & $\mathrm{a}(16)$ & $\mathrm{a}, \mathrm{i}(21)$ & m (18) & & n (24) & $\mathrm{a}(22)$ & $\mathrm{f}(17)$ \\
\hline Anxiety & $\mathrm{g}(27)$ & h (20) & $\mathrm{p}(18)$ & $\mathrm{h}(26)$ & $\mathrm{p}(21)$ & $\mathrm{g}(18)$ & $\mathrm{g}(34)$ & $\mathrm{h}(20)$ & o (12) \\
\hline Eternity & $\mathrm{n}(20)$ & $\mathrm{j}(18)$ & e (14) & $\mathrm{m}, \mathrm{n}(21)$ & $\mathrm{j}(15)$ & & $\mathrm{n}(20)$ & $\mathrm{j}(19)$ & $\mathrm{a}(16)$ \\
\hline Anger & $\mathrm{p}(51)$ & o (16) & $\mathrm{h}(14)$ & $\mathrm{p}(46)$ & $\mathrm{h}(15)$ & o (10) & $\mathrm{p}(46)$ & o (19) & $\mathrm{h}(9)$ \\
\hline Creation & $\mathrm{k}(15)$ & $\mathrm{n}(14)$ & $1(11)$ & e (18) & n (16) & $\mathrm{i}(10)$ & $\mathrm{k}(20)$ & i (10) & $\mathrm{c}, \mathrm{p}(9)$ \\
\hline Loneliness & c (34) & \multicolumn{2}{|c|}{ b, k (14) } & $1(22)$ & $\mathrm{c}(15)$ & $\mathrm{b}(10)$ & $\mathrm{b}(16)$ & $\mathrm{k}(12)$ & $\mathrm{g}, 1(11)$ \\
\hline Surprise & $\mathrm{n}(47)$ & $\mathrm{f}(30)$ & m (9) & $\mathrm{n}(24)$ & $f(16)$ & o (11) & $\mathrm{n}(22)$ & $\mathrm{f}(21)$ & m(16) \\
\hline Destruction & $\mathrm{p}(37)$ & $\mathrm{h}(20)$ & o (19) & $\mathrm{p}(39)$ & o (31) & $\mathrm{h}(13)$ & $\mathrm{p}(48)$ & o (18) & h (14) \\
\hline Fear & o (20) & h (19) & $\mathrm{g}(18)$ & h (24) & $\mathrm{p}(16)$ & $\mathrm{g}(11)$ & $\mathrm{g}(25)$ & h (17) & o (16) \\
\hline Time & e (18) & $\mathrm{i}(11)$ & $\mathrm{m}(10)$ & $\mathrm{j}(18)$ & $\mathrm{n}(16)$ & $\mathrm{f}(13)$ & e (22) & $\mathrm{n}(13)$ & $\mathrm{a}, \mathrm{j}, \mathrm{m}(11)$ \\
\hline West & \multicolumn{3}{|c|}{ Germany $(n=75)$} & \multicolumn{3}{|c|}{ Serbia $(n=100)$} & \multicolumn{3}{|c|}{ Slovakia $(\mathrm{n}=61)$} \\
\hline Happiness & $\mathrm{m}(28)$ & $\mathrm{a}(25)$ & $\mathrm{n}(17)$ & $\mathrm{a}(24)$ & $\mathrm{n}(19)$ & i (17) & $\mathrm{n}(28)$ & $\mathrm{m}(21)$ & e (16) \\
\hline Anxiety & $\mathrm{g}(28)$ & h (17) & $\mathrm{p}(15)$ & $\mathrm{g}(22)$ & $\mathrm{d}(16)$ & $1(14)$ & $\mathrm{d}(16)$ & $\mathrm{g}, \mathrm{h}(15)$ & \\
\hline Eternity & $\mathrm{n}(25)$ & $\mathrm{a}(19)$ & $\mathrm{j}(13)$ & $f(24)$ & e (20) & $\mathrm{j}(17)$ & $\mathrm{j}(20)$ & e (18) & $\mathrm{n}(13)$ \\
\hline Anger & $\mathrm{p}(30)$ & o (23) & $\mathrm{g}(16)$ & $\mathrm{p}(35)$ & $\mathrm{h}(22)$ & o (13) & $\mathrm{p}(38)$ & $\mathrm{g}(18)$ & o (13) \\
\hline Creation & \multicolumn{3}{|c|}{$\mathrm{j}, \mathrm{k}, \mathrm{n}(13)$} & o (35) & $\mathrm{p}(10)$ & gkl (9) & $\mathrm{a}(30)$ & n (15) & $\mathrm{j}(10)$ \\
\hline Loneliness & $\mathrm{b}(21)$ & $1(13)$ & $\mathrm{c}, \mathrm{k}(11)$ & b (29) & $\mathrm{c}(15)$ & $\mathrm{k}(11)$ & $\mathrm{k}(16)$ & a (13) & b, $1(11)$ \\
\hline Surprise & n (17) & e (12) & $\mathrm{k}(11)$ & $\mathrm{n}(21)$ & m (15) & $\mathrm{j}, 1(12)$ & $\mathrm{c}, \mathrm{m}(15)$ & $\mathrm{p}(11)$ & \\
\hline Destruction & $\mathrm{p}(42)$ & $\mathrm{h}(25)$ & $\mathrm{g}(13)$ & $\mathrm{p}(40)$ & $g(17)$ & $\mathrm{h}(11)$ & h (28) & $\mathrm{p}(22)$ & o (18) \\
\hline Fear & $\mathrm{g}(19)$ & h (16) & o (15) & h (17) & $\mathrm{g}(15)$ & $\mathrm{p}(13)$ & $\mathrm{g}(26)$ & h (16) & 1, o (11) \\
\hline Time & $b, f(16)$ & $\mathrm{a}(12)$ & & e (23) & $f(20)$ & n (14) & n (16) & $\mathrm{b}(15)$ & e (13) \\
\hline
\end{tabular}

Note. The numbers in parentheses indicate the percentages of matches to the specified form. 


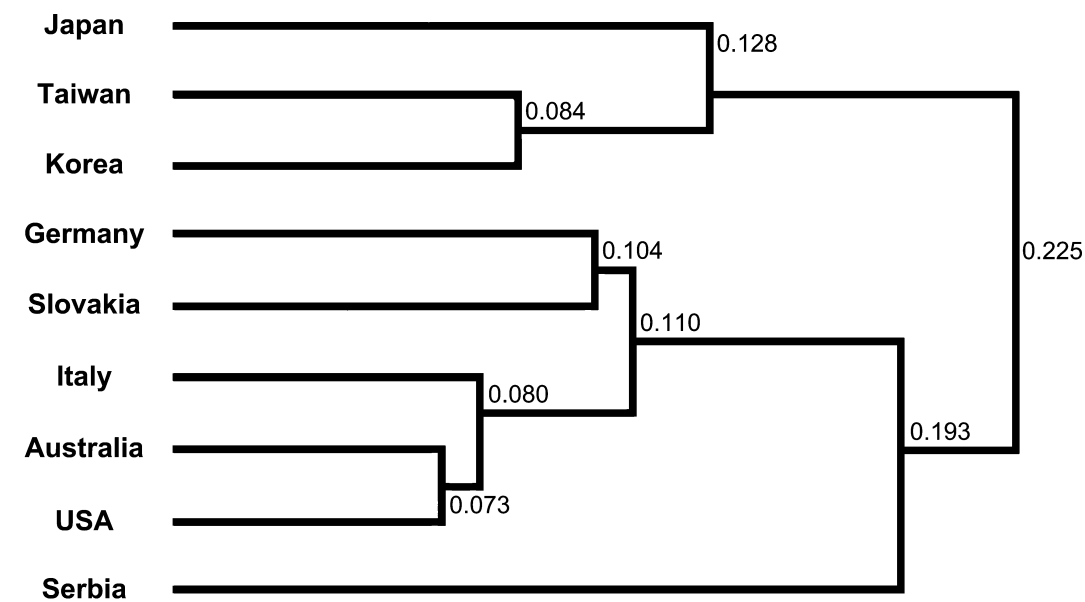

Fig. 2. Results of the Ward minimum-variance cluster-analysis of the word-form matchings in nine different regions of the world. Values represent semipartial $R$-squared.

frequently matched to the word "Time", and moderately complex irregular forms like $g$ and $h$ were frequently matched to the words "Anxiety" and "Fear".

For each of the nine regions, a $10 \times 16$ table showing the matching frequencies between the 10 words and 16 forms was made. Statistical analyses revealed high Spearman's correlations (.54 to .81) between the matching frequencies in these tables across the different languages and regions. All correlations were significantly greater than the critical value of $.20(p<.01, d f=158)$. The highest correlation $(.81)$ was found between Taiwan and Korea, and the second highest (.80) was found between Italy and Australia, countries that do not share the same language. Moderately high correlations were found between the US and Australia (.78), where the primary language of both countries is English, and between Japan and Taiwan (.73), which share many language characters although their pronunciations differ. Correlations also were high within the Eastern group of regions (.73 to .82) and within the Western group (.61 to .81), but slightly smaller across the two groups (.54 to .73). The median test indicated that this difference was significant $\left(\chi^{2}(1, N=36)=5.44, p<0.5\right)$.

These results demonstrated that forms are associated with similar meanings to individuals of many different languages in different geographical regions. However, more detailed statistical analysis revealed subtle differences between the East and West. A Ward minimum-variance cluster analysis was applied to the same data and the results are presented in Fig. 2. This analysis is a classification method that is used to arrange a set of cases into hierarchical clusters. Particularly, the Ward (1963) method attempts to minimize the sum of squares of the two clusters that can be formed at each step. These results reveal that the word-form matching in the nine regions is divided into two large clusters, i.e. the Eastern and the Western clusters, although the results of Serbia are relatively separated from the main Western cluster. The slight difference in the Serbian sample in comparison to the other Western regions may reflect the historical and cultural 
differences between Serbia and the other regions. It should be noted that the maximum semi-partial $R$-squared value is only 0.221 , indicating that differences between the East and West with respect to word-form matching are rather small. These differences may reflect cultural differences in the affective meanings of words or concepts such as "Happiness" and "Loneliness", rather than the cultural differences in the affective meaning of forms; this possibility is explored in Experiment 2.

\section{EXPERIMENT 2:}

\section{Measurement of the AfFective Meaning of Words ANd Forms}

To compare cross-regional differences in affective meanings between words and forms, the Semantic Differential (SD) technique (Osgood, Suci, \& Tannenbaum, 1955) was employed with stimulus words and forms in two independent groups in each of four regions. Japan and Taiwan were chosen from the Eastern group and the US and Serbia were chosen from the Western group, because the respective researchers of these regions were particularly interested in this study.

\section{METHOD}

Participants. Undergraduate students in each of four geographical regions: 30 for words and 30 for forms in Japan; 67 and 49 respectively in Taiwan; 25 and 27 respectively in the US; and 24 and 25 respectively in Serbia participated in the SD experiment on words and forms ( $20 \%$ to $41 \%$ in each group were males). None of the students had participated in Experiment 1. All participants were native speakers of the primary language of their region, speaking Japanese, Chinese, English or Serbian. All participants were between the ages of 17 to 25 , with the exception of one 30 year-old participant in Taiwan.

Stimulus materials. The same 10 stimulus words used in Experiment 1 were used in Experiment 2 and were presented in Japanese, Chinese, English and Serbian. Eight of the 16 stimulus forms used in Experiment 1 were adopted for Experiment $2(a, b, c, d, m, n, o$ and $p$ in Fig. 1). The number of stimulus forms was reduced to eight because rating all 16 forms on the $11 \mathrm{SD}$ scales was judged to be too time-intensive for participants, and the amplitude differences in wave form had not been found to be so important in either Oyama et al. (2003) MDS study or the present Experiment 1. The eight adopted forms differed from the others only with respect to the amplitude.

For the SD measurement, 11 seven-point scales were utilized which were selected on the basis of the results of a series of studies on affective meanings of various sensory stimuli, colors, forms, sounds, music and movies (Oyama, Takimoto, \& Iwasawa, 1993; Oyama, Yamada, \& Iwasawa, 1998b). Three of these scales represent each of three factors, Evaluation, Activity, and Lightness, while two represent the fourth factor, Sharpness, as revealed by Oyama et al. (1993). The adjective pairs used in the 11 SD scales were as follows: 1) Evaluation scales: good-bad, favorite-unfavorite, beautiful-ugly; 2) Activity scales: noisy-quiet, dynamicstatic, joyful-sober; 3) Lightness scales: light-heavy, bright-dark, cheerful-gloomy; and 4) Sharpness scales: tense-loose, sharp-blunt. These adjective pairs were translated from the Japanese language by referring to previous studies (Tanaka et al., 1963; Oyama et al., 1963) and were checked by a native English speaker (Oyama et al., 1998b). The Chinese and Serbian versions were translated by native speakers of these languages from the Japanese and English versions, respectively.

Biserial correlation analyses performed by Oyama, Yamada and Iwasawa (1998a) revealed significant relationships between the physical parameters of the stimulus forms and the factor scores of the affective dimensions. Specifically, the regularity or the absence of random modulation in the forms was correlated with the "Evaluation" and "Lightness" factors, the frequency of the waves composing the forms was 
Happiness

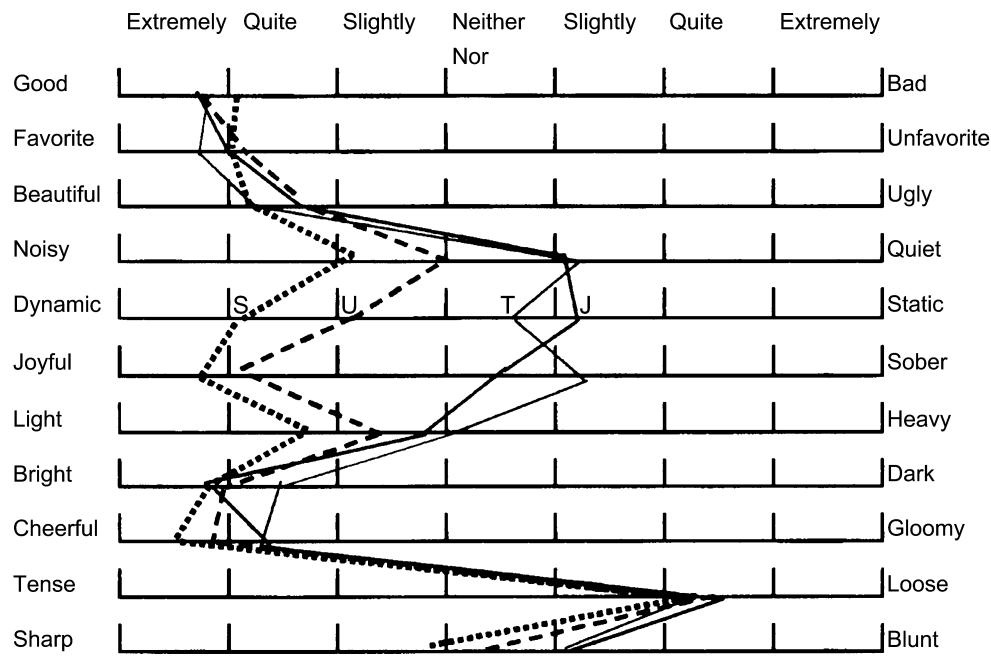

\section{Surprise}

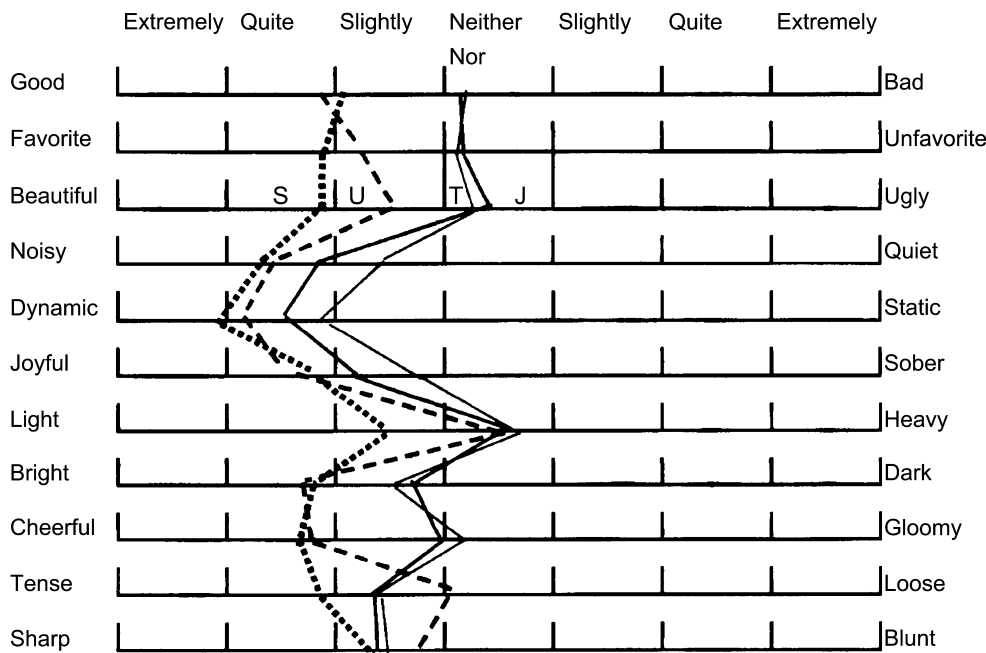

Fig. 3. Comparison of semantic profiles of the words "Happiness" and "Surprise" between the four geographical regions, Japan (J), Serbia (S), Taiwan (T), and the USA (U).

correlated with the "Activity" factor, and the stimulus linearity was correlated with the "Sharpness" factor.

Procedure. Experimental sessions were conducted in groups in classrooms. The participants were administered a set of SD forms that also contained blanks for the participant's name, gender, age, and native language in the top portion. For the word-rating group, 10 sets of the 11 seven-point SD scales as shown in Fig. 3 followed these blanks and one of the 10 words was printed above each set of the SD scales. For the 


\section{Form a}

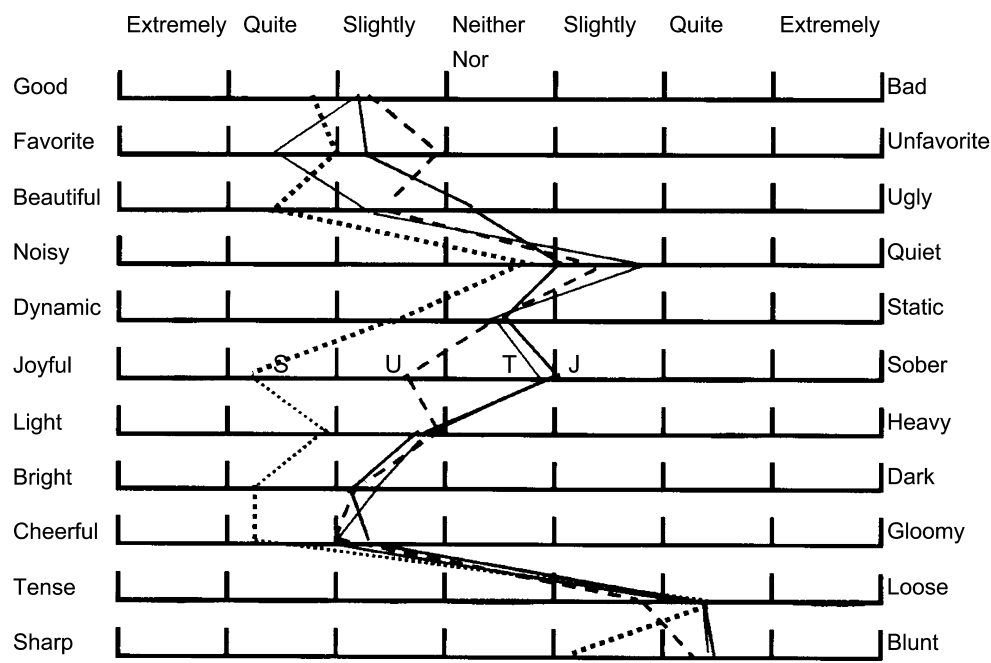

\section{Form $\boldsymbol{m}$}

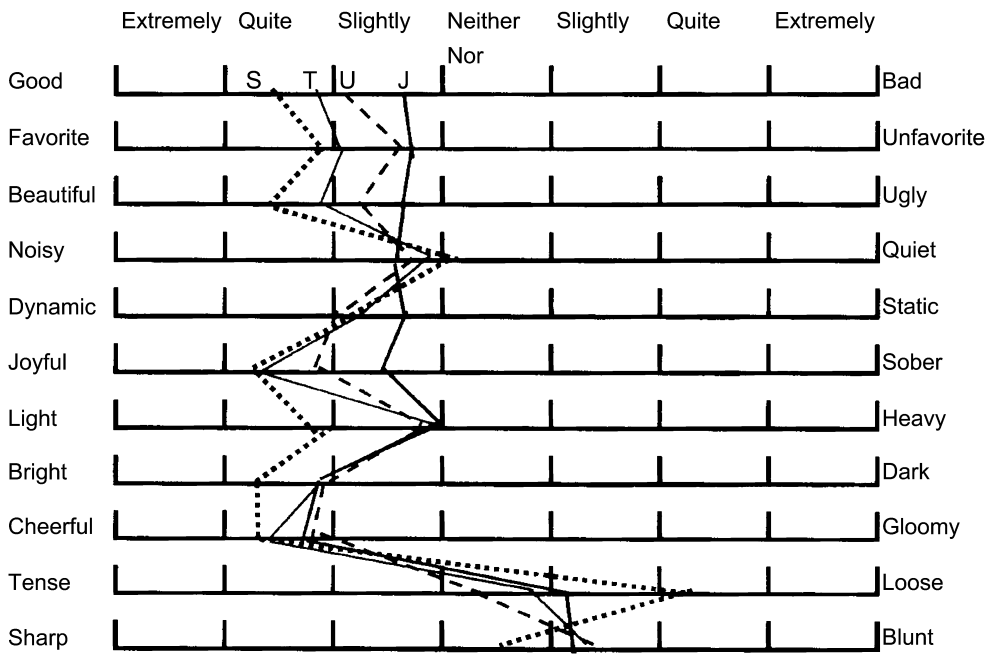

Fig. 4. Comparison of the semantic profiles of Forms $a$ and $m$ between the four geographical regions, Japan (J), Serbia (S), Taiwan (T), and the USA (U).

form-rating group, eight sets of scales were provided and the number of the form was printed above each set of scales. In Japan, Taiwan and the US, a separate sheet of paper on which the eight stimulus forms were printed was given to each participant. In Serbia, the stimulus forms were presented on a screen by an overhead projector. Participants were instructed to complete the blanks and rate every word or form on the SD scales. 
Table 4. Ranges and Medians (in parenthesis) of Correlations of Semantic Profiles for the 10 Words and the Eight Forms among the Four Regions

\begin{tabular}{llcc}
\hline & \multicolumn{1}{c}{ Regions } & Words & Forms \\
\hline Within Reginal Groups & Japan-Taiwan & $.69-.97(.93)$ & $.81-.98(.90)$ \\
& US-Serbia & $.67-.98(.87)$ & $.64-.96(.77)$ \\
Between Regional Groups & Japan-US & $.52-.91(.83)$ & $.70-.94(.88)$ \\
& Japan-Serbia & $.67-.88(.83)$ & $.57-.84(.71)$ \\
& US-Taiwan & $.39-.96(.84)$ & $70-.94(.87)$ \\
& Taiwan-Serbia & $.61-.96(.83)$ & $49-.93(.84)$ \\
\hline
\end{tabular}

\section{RESULTS}

The average semantic profiles of the words and forms were compared across the four geographic regions. Figs 3 and 4 show some examples, such as the semantic profiles of the words "Happiness" and "Surprise", as well as Forms $a$ and $m$, in the four geographic regions.

Average ratings of each of the 10 stimulus words were compared across the four geographic regions. Pearson's correlations of the ratings of each word on the 11 scales among the four regions ranged from .39 to .98, as shown in Table 4. Most correlations were statistically significant $(p \mathrm{~s}<.05, d f=9)$. The correlations were significantly larger between regions within the same group than those across the Eastern and Western groups as shown by the median test $\left(\chi^{2}(1, N=60)=4.80, p<0.05\right)$. Such inter-group differences were especially salient for such words "Loneliness", "Surprise", "Time", and "Happiness". For example, the correlation coefficients between Taiwan and the US, which showed the least similarity in the rating among the four regions, on the above four words were $.39, .44, .47$, and .77 , respectively, and only the latter coefficient was significant, $p<.01, d f=9$, though the correlations were higher than .90 for the other words, with the exception of a medium value of .45 for the word "Eternity". These results suggest the presence of regional differences in the affective meanings of such words. Similar differences were already found by Oyama et al. (1963) between the Japanese and American participants for the words "Loneliness" and "Happiness".

Fig. 3 shows semantic profiles for the words "Happiness" and "Surprise". It indicates that the ratings on the three Activity-related scales for "Happiness" were generally higher in the US and Serbia than in Japan and Taiwan. These differences between the Eastern and Western regions were found to be highly significant using as shown by the Tukey's HSD method (HSDs $=1.035$ and $0.849, p \mathrm{~s}<.01$ and 0.05 , respectively, $d f=15730$, in which error variances in a three-way ANOVA were pooled, the number of repetitions in all areas was assumed to be 24 which is the $N$ of the smallest participant group in an effort to make the statistical tests simple but rather conservative and critical values of the studentized range statistics $q$ were those for $d f=120$ ). The 
differences were larger than one-point on the seven-point scales and would also be significant in a practical psychological sense. These results show that "Happiness" generally means quiet and peaceful for the participants in the Eastern group, whereas it generally indicated excitement for participants in the Western group. This may explain the tendency for participants in the Eastern regions to match Form $a$ to "Happiness" in Experiment 1, whereas those in the Western regions matched Form $m$ to "Happiness", because Form $a$ was rated as less active than Form $m$ in all regions, as shown in Fig. 4. The word "Surprise" also was rated consistently lower in Japan and Taiwan than in the US and Serbia on the three Evaluation-related scales as shown in Fig. 3. Most differences in the related scales across the East and West were significant beyond the above-mentioned $H S D$ s. This tendency corresponds well to the trend found in Experiment 1 that irregular forms, which were lowly evaluated in Experiment 2, had been matched to the word "Surprise" slightly more frequently in the East than in the West $34.4 \%$ in the East and $25.5 \%$ in the West, $\left.\chi^{2}(1, N=757)=6.78, p<0.01\right)$, while majorities had matched regular forms to it in both the Eastern and Western groups of regions. However, it was difficult to find clear relationships between the word-form matching and the affective meanings for the stimulus words "Loneliness" and "Time" in the Eastern and Western groups of regions.

The semantic profiles of each stimulus form were generally comparable across the four geographic regions as the examples shown in Fig. 4. Pearson's correlations of the profiles of each form between different regions were especially high among Japan, Taiwan and the US (.70 to .98 , all correlations significant, $p \mathrm{~s}<.05, d f=9)$, even across the Eastern and Western groups.

Correlations between Serbia and the other regions were somewhat smaller (.49 to .96 , with 3 of the 24 correlations not reaching the significance level of $p<.05, d f=9$ ), as shown in Table 4. Some significant differences were found in the average ratings between Serbia and the other regions as presented in Fig. 4 (HSDs $=1.170$ and 0.959 for $p s<.01$ and .05 , respectively, $d f=11088$, where the error variances were pooled, the numbers of repetitions were again assumed to be 25 as in the $N$ of the smallest participant group, and critical values of the studentized range statistics $q$ were those for $d f=120$ ). This was possible due to differences in the presentation method, because the forms were presented by an overhead projector in Serbia, whereas they were printed on a sheet of paper given to each participant in the other regions. Moreover, according to one of the authors who conducted the experiment for the Serbian participants, the Serbian participants had previous experience in abstract pattern judgments, and for this reason, they perhaps did not hesitate to give more extreme judgments. This may also have caused differences in the profiles. The stimulus forms have no special meanings in Serbian culture.

To compare the semantic profiles across words and forms, correlations were also obtained for all combinations between them. Table 5 shows the most highly correlated three forms for each of the ten words in the four regions. This table cannot be compared directly with the results of Experiment 1 shown in Tables 2 and 3, because only half of the stimulus forms were used in Experiment 2. However, the following general tendencies can be identified from this table. Regular forms share similar semantic profiles with 
Table 5. The Most Highly Correlated Three Forms to the 10 Words in the Four Regions

\begin{tabular}{|c|c|c|c|c|c|c|c|c|c|c|c|c|}
\hline \multirow{2}{*}{$\begin{array}{c}\text { Words } \\
\text { Happiness }\end{array}$} & \multirow[b]{2}{*}{$\mathrm{a}(.90)$} & \multicolumn{2}{|l|}{ Japan } & \multicolumn{3}{|c|}{ Taiwan } & \multicolumn{3}{|c|}{ US } & \multicolumn{3}{|c|}{ Serbia } \\
\hline & & $\mathrm{m}(.67)$ & $\mathrm{b}(.36)$ & $\mathrm{a}(.94)$ & $\mathrm{m}(.65)$ & $\mathrm{c}(.62)$ & $\mathrm{a}(.88)$ & $\mathrm{m}(.72)$ & $\mathrm{c}(.67)$ & $\mathrm{m}(.94)$ & c $(.94)$ & $\mathrm{a}(.92)$ \\
\hline Anxiety & $\mathrm{d}(.79)$ & $\mathrm{p}(.70)$ & $\mathrm{n}(.58)$ & $\mathrm{p}(.90)$ & $\mathrm{d}(.86)$ & n (.69) & $\mathrm{p}(.90)$ & $\mathrm{d}(.87)$ & $\mathrm{n}(.62)$ & $\mathrm{d}(.67)$ & $\mathrm{b}(.54)$ & $\mathrm{n}(.41)$ \\
\hline Eternity & $\mathrm{b}(.58)$ & a (.47) & $\mathrm{m}(.20)$ & $\mathrm{a}(.77)$ & m (.39) & $\mathrm{b}(.38)$ & $\mathrm{m}(.59)$ & $\mathrm{a}(.57)$ & $\mathrm{c}(.30)$ & $\mathrm{m}(.78)$ & $\mathrm{a}(.73)$ & c (.64) \\
\hline Anger & $\mathrm{p}(.93)$ & $\mathrm{d}(.81)$ & $\mathrm{n}(.77)$ & $\mathrm{p}(.94)$ & $\mathrm{d}(.88)$ & $\mathrm{n}(.79)$ & $\mathrm{p}(.90)$ & $\mathrm{d}(.84)$ & $\mathrm{n}(.49)$ & $\mathrm{d}(.93)$ & $\mathrm{p}(.65)$ & $\mathrm{n}(.52)$ \\
\hline Creation & $\mathrm{a}(.58)$ & $\mathrm{m}(.40)$ & $\mathrm{b}(.33)$ & $\mathrm{m}(.83)$ & $\mathrm{a}(.77)$ & c $(.75)$ & $\mathrm{a}(.74)$ & $\mathrm{m}(.69)$ & $\mathrm{c}(.42)$ & $\mathrm{a}(.72)$ & $\mathrm{m}(.71)$ & $\mathrm{c}(.69)$ \\
\hline Lonliness & $\mathrm{b}(.30)$ & $\mathrm{d}(.30)$ & $\mathrm{n}(.13)$ & $\mathrm{b}(.38)$ & $\mathrm{a}(.08)$ & - & $\mathrm{d}(.76)$ & $\mathrm{p}(.63)$ & $\mathrm{b}(.52)$ & $\mathrm{b}(.36)$ & $\mathrm{d}(.29)$ & $\mathrm{n}(.08)$ \\
\hline Surprise & $\mathrm{p}(.85)$ & $\mathrm{o}(.78)$ & $\mathrm{n}(.73)$ & $\mathrm{n}(.88)$ & $\mathrm{p}(.77)$ & d (.69) & c $(.77)$ & $\mathrm{m}(.66)$ & $\mathrm{o}(.58)$ & $\mathrm{o}(.61)$ & $\mathrm{d}(.11)$ & $\mathrm{n}(.11)$ \\
\hline Destruction & $\mathrm{p}(.92)$ & $\mathrm{d}(.80)$ & $\mathrm{n}(.73)$ & $\mathrm{p}(.91)$ & $\mathrm{d}(.82)$ & $\mathrm{n}(.75)$ & $\mathrm{p}(.88)$ & $\mathrm{d}(.78)$ & o (.60) & $\mathrm{d}(.93)$ & $\mathrm{p}(.64)$ & $\mathrm{n}(.49)$ \\
\hline Fear & $\mathrm{d}(.83)$ & $\mathrm{p}(.69)$ & $\mathrm{n}(.64)$ & $\mathrm{p}(.86)$ & $\mathrm{d}(.83)$ & $\mathrm{n}(.61)$ & $\mathrm{d}(.84)$ & $\mathrm{p}(.81)$ & b (.44) & $\mathrm{d}(.87)$ & $\mathrm{n}(.49)$ & b (.46) \\
\hline Time & $\mathrm{b}(.37)$ & $\mathrm{a}(.21)$ & $\mathrm{m}(.01)$ & $\mathrm{a}(.41)$ & $\mathrm{c}(.20)$ & $\mathrm{m}(.10)$ & $\mathrm{b}(.45)$ & $\mathrm{m}(.34)$ & $\mathrm{a}(.27)$ & $\mathrm{m}(.71)$ & $\mathrm{a}(.71)$ & $\mathrm{c}(.68)$ \\
\hline
\end{tabular}

Note: The numbers in parentheses indicate correlations

words such as "Happiness", "Eternity" and "Time", whereas irregular forms do so with words such as "Anxiety", "Anger", "Destruction" and "Fear". The chi-square test applied to a two word-categories $\mathrm{x}$ two form-types classification table revealed highly significant associations $\left(\chi^{2}(1, N=84)=15.14, p<.001\right)$. Simple forms share similar profiles with the words, "Creation" and "Loneliness", whereas complex forms do so with the word "Surprise". This tendency was also significant $\left(\chi^{2}(1, N=36)=4.03, p<.05\right)$. Correlations of profiles between the word "Happiness" and Form $m$ are smaller in Japan and Taiwan than in the US and Serbia, though these differences do not reach a significance level. These tendencies are very similar to those found for direct matches between words and forms in Experiment 1.

\section{GENERAL DisCUSSION}

In Experiment 1, word-form matching between 10 abstract words and 16 computergenerated nonsense forms was performed by participants in nine geographical regions of the world who were native speakers of eight different languages: Japanese, Chinese, Korean, English, Italian, German, Serbian and Slovakian. The results revealed similar trends across languages and geographical regions. Many participants in each region matched regular forms to the words "Happiness" and "Eternity", complex regular straightline forms to the word "Surprise", simple irregular forms to the words "Loneliness" and "Creation", and complex irregular, usually straight line forms to the words "Anger" and "Destruction". Moderately complex regular forms were frequently matched to the word "Time", and moderately complex irregular forms were frequently matched to the words "Anxiety" and "Fear". Statistical analyses showed generally strong correlations across different languages and different geographical regions. Correlations were especially 
strong between regions within the Eastern group and within the Western group, but were slightly weaker across the two groups. These differences may be based on regional differences in the affective meanings of words or concepts such as "Happiness" and "Surprise", rather than regional differences in the affective meaning of forms. Cultural differences between East and West in the meanings of "Happiness" have already been discussed by Uchida, Norasakkunkit, and Kitayama (2004). They reviewed many related empirical studies and concluded that happiness tends to be defined and experienced as a realization of social harmony in East Asian cultures, but as personal achievement in European-American cultures.

The above-mentioned hypothesis was tested in Experiment 2, in which the affective meanings of the 10 words and eight of the 16 forms used in Experiment 1 were measured using the Semantic Differential technique in four geographical regions: Japan, Taiwan, the US, and Serbia. Average ratings of each stimulus word on the 11 SD scales were compared across the geographical regions. All Pearson's correlations of the ratings of each word were statistically significant between regions within the same geographical group, but rather weak between regions across the Eastern and Western groups, especially for such words as "Loneliness", "Surprise", "Time" and "Happiness". These results suggest regional differences in the affective meanings of these words. However, average ratings on each stimulus form were largely similar across regions and across the East and West, particularly for Japan, Taiwan and the US, where the stimulus forms were presented in the same manner on a printed sheet.

These results re-confirmed the cross-regional similarity of form symbolism with a greater variety of forms and languages than those examined in Kennedy et al. (2002), and suggest that form symbolism is not primarily based on knowledge and past experiences in individual cultures including different writing-systems, such as phonographic versus ideographic. It is possible that form symbolism is mainly based on more basic and common affective, or some other mediation processes produced by the sensory features of the stimuli. For example, pleasantness appears to be associated with the regularity of the form, activity appears to be associated with the complexity of the form, and sharpness appears to be associated with the straightness of the form. The cross-regional similarity of affective meaning was previously addressed by Osgood (1962) and others. As Collier (1996) and Oyama et al. (1998b) indicated, synesthetic tendencies might play important roles in form symbolisms. The cross-regional similarity of synesthetic tendencies shown by Osgood (1960) likely plays a role in the cross-regional and cross-language similarity of form symbolism found in the present study.

Slight differences between the Eastern and Western groups found in the word-form matching experiments may be attributed to differences between the two groups in the affective meanings of words rather than forms, as suggested by the results of the Semantic Differential experiment. It is possible that the differences found between the Eastern and Western groups in the word-form matching experiment were caused by the slight semantic differences between the Japanese and English versions of the stimulus words, from which the stimulus words for the other regions in the Eastern and Western groups were translated. If this is the case, the net cross-regional differences would be smaller, not 
larger, than the observed differences.

Cross-regional similarities of form symbolisms found in this study also suggest the importance of visual signs, symbols, designs, art and logo used for international communication (Arnheim, 1974; Berlyne, 1976; Henderson, Cote, Leong, \& Schmitt, 2003; Oyama, 2003).

\section{REFERENCES}

Arnheim, R. 1974. Art and visual perception. A psychology of the creative eye. Berkley, CA: University of California Press.

Berlyne, D. A. 1976. Similarity and preference judgments of Indian and Canadian subjects exposed to Western paintings. International Journal of Psychology, 11, 43-55.

Collier, G. L. 1996. Affective synesthesia: Extracting emotion space from simple perceptual stimuli. Motivation and Emotion, 20, 1-32.

Fox, C. W. 1935. An experimental study of naming. American Journal of Psychology, 47, 545-579.

Henderson, P. W., Cote, J. A. Loeng, S. M., \& Schmitt, B. 2003. Building strong brands in Asia: selecting the visual components of image to maximize brand strength. Research in Marketing, 20, 297-313.

Kennedy, J. M., Liu, C. H., Challis, B. H., \& Kennedy, V. 2002. Form symbolism across languages: Danish, Slovene and Japanese. In C. Zelinsky (Ed.). Text transfer: Metaphors, translation and expert-lay communication (pp. 229-247). Berlin: Mouton de Gruyter.

Köhler, W. 1929. Gestalt psychology. New York: Liveright.

Kwon,Y. G., \& Park, J. E. 2005. A study on the therapeutic color design method in residential space. Journal of Korean Society of Color Studies, 19, 11-20. In Korean with English summary.

Lai, C. C. 2003. Color psychology for design. Taipei: Hsuchun Wenhua Hsuyeh Yuosen Gonshu. In Chinese.

Lindauer, M. 1990. Meanings of physiognomic stimuli takete and maluma. Bulletin of Psychonomic Society, 28, 47-50.

Liu, C. H., \& Kennedy, J. M. 1993. Symbolic forms and cognition. Psyke \& Logos, 14, 441-456.

Liu, C. H., \& Kennedy, J. M. 1997. Form symbolism, analogy and metaphor. Psychonomic Bulletin and Review, 4, 546-551.

Marks, L. E. 1996. On perceptual metaphors. Metaphor and Symbolic Activity, 11, 39-66.

Osgood, C. H. 1960. A cross-cultural generality of visual-verbal synesthetic tendencies. Behavioral Science, 5, 146-169.

Osgood, C. E. 1962. Studies on the generality of affective meaning systems. American Psychologist, 17, 10 28.

Osgood, C. E., Suci, G. J., \& Tannenbaum, P. H. 1955. The measurement of meaning. Urbana, IL: University of Illinois Press.

Oyama, T. 2003. Affective and symbolic meanings of color and form: Experimental psychological approaches. Empirical Studies of Arts, 21, 137-142.

Oyama, T., \& Haga, J. 1963. Common factors between figural and phonetic symbolism. Psychologia (Kyoto), 6, 131-144.

Oyama, T., Miyano, H., \& Yamada, H. 2003. Multidimensional scaling of computer-generated abstract forms. In H. Yanai, A. Okada, K. Shigemasu, Y. Kano, \& J. J. Meulman (Eds.) New developments in psychometrics pp. 551-558. Tokyo: Springer.

Oyama, T., Takimoto, S., \& Iwasawa, H. 1993. A study on synesthetic tendencies by means of Semantic Differential technique. Japanese Journal of Behaviormetrics, 20, 55-64. In Japanese with English summary.

Oyama, T., Tanaka, Y., \& Haga. J, 1963. Color-affection and color-symbolism in Japanese and American students. Japanese Journal of Psychology, 34,110-121. In Japanese with English summary.

Oyama, T., Yamada, H., \& Iwasawa, H. 1998a. Symbolic meanings of computer-generated abstract forms. Psychological Research, Nihon University, 19, 4-9. 
Oyama, T., Yamada, H., \& Iwasawa, H., 1998b. Synesthetic tendencies as the basis of sensory symbolism: A review of a series of experiments by means of semantic differential. Psychologia (Kyoto), 41, 203215.

Schale, K. W. 1961. Scaling the association between colors and mood tones. American Journal of Psychology, 74, 266-273.

Scheerer, M., \& Lyons, J. 1957. Line drawings and matching responses to words. Journal of Personality, 25, 251-273.

Seitz, J. A. 1998. Nonverbal metaphor: A review of theories and evidence. Genetic, Social \& General Psychology Monographs, 124, 95-119.

Tanaka, Y., Oyama, T., \& Osgood, C.E. 1963. A cross-cultural and cross-concept study of generality of semantic spaces. Journal of Verbal Learning and Verbal Behavior, 2, 392-405.

Uchida, Y., Norasakkunkit, V., \& Kitayama, S. 2004. Cultural constructions of happiness: Theory and empirical evidence. Journal of Happiness Studies, 5, 223-239.

Ward, J. H. Jr. 1963. Hierarchical grouping to optimize an objective function. Journal of American Statistical Association, 58, 236-244.

Werner, H., \& Kaplan, B. 1963. Symbol formation: An organismic-developmental approach to language and the expression of thought. New York: Wiley.

Zusne, L. 1970. Visual form perception. New York: Academic Press.

Zwimpfer, M. 1985. Farbe: Licht, Sehen, Empfindung_Elementare Farbenlehre in Bildern. Berlin: Verlag Paul Haupt. 